Journal of Accident and Emergency Medicine 1994 11, 189-191

\title{
Use of ketamine in prolonged entrapment
}

\author{
R. COTTINGHAM ${ }^{1}$ \& K. THOMSON ${ }^{2}$
}

${ }^{1}$ Royal Free NHS Trust Hospital, Pond Street, Hampstead, and ${ }^{2}$ Heatherwood Hospital, Ascot, Berkshire

\section{SUMMARY}

This paper discusses the advantages of ketamine analgesia in the management of trapped patients after serious incidents. Four case histories and a review of the literature lead us to the conclusion that ketamine is the drug of choice in these situations.

Key words: anaesthetic, emergency medical care, ketamine, road traffic accident

\section{INTRODUCTION}

Rapid, safe and painfree extrication of trapped casualties is the over-riding concern of the emergency services after a serious incident. Under these circumstances, entonox or opiates are usually administered for pain relief.

Ketamine, which possesses both analgesic and anaesthetic properties, has been available in Britain since $1970^{1}$ to provide analgesia and anaesthesia. Its use has been described not only in hospital, both for elective $e^{2,3}$ and emergency procedures ${ }^{4,5}$ but also in battle casualties. ${ }^{6}$

Four cases are presented where ketamine has been used successfully as the anaesthetic or analgesic agent during release from prolonged entrapments. The longest recorded out-of-hospital anaesthetic with ketamine (over $4 \mathrm{~h}$ ) is described in Case 1.

\section{CASE REPORTS}

Case 1. A Mercedes recovery truck collided with another similar vehicle which was stationary on the hard shoulder on a British motorway. The legs of the 32-year-old male driver were trapped and buried in wreckage. He had no significant injuries above the pelvis, but had bilateral compound widely separated femoral fractures.

Immediate resuscitation and stabilization included two wide-bore i.v. lines and oxygen by face-mask. It was envisaged that entrapment would be prolonged, and as he was conscious and in severe pain, an anaesthetist (KT) was called specifically to provide adequate analgesia.

Ketamine $50 \mathrm{mg}$ was administered intravenously, followed by $25 \mathrm{mg}$ bolus doses at approximately 15-min intervals. This provided satisfactory analgesia without change in blood pressure or loss of the airway. A total of $5 \mathrm{~L}$ of degraded collagen (Haemaccel), $2 \mathrm{~L}$ of Hartmann's solution and 4 units of 'O' Rhesus negative blood were administered during the extrication. Non-invasive blood pressure, oxygen saturation and ECG were monitored throughout using a Propaq 105.

Six months later the patient was reviewed by KT. His only residual disability was a slight limp. He had no recollection of the accident or subsequent events of that day.

Case 2. A 67-year-old woman was driving in very heavy rain along a dual carriageway in a Vauxhall saloon when she was in head-on collision with an out-of-control van which had crossed the central reservation. She was trapped by severe structural deformation of her vehicle. Her most serious injuries were bilateral femoral shaft fractures and a degloving injury of the upper face with bilateral globe rupture. She remained conscious but was very distressed and in great pain.

Fluid resuscitation and oxygen therapy were started, but the BASICS (British Association for Immediate Care) doctor on scene considered that opiate pain relief was contraindicated. There was a risk that neither hypoventilation or airway obstruction could not be treated because of intruding metalwork, and so backup was sought from one of the authors (RC) who arrived some $20 \mathrm{~min}$ into the incident. The patient was haemodynamically stable with good intravenous access and a Coma Scale of 15.

After the procedure had been explained to the patient, she was given ketamine by incremental $25 \mathrm{mg}$ bolus intravenous injection to a total of $75 \mathrm{mg}$. She remained normotensive with a satisfactory airway and the excellent analgesia allowed rapid painless extrication. Total entrapment time was 
approximately $50 \mathrm{~min}$. Sadly, she remained blind, but otherwise made an uneventful recovery. She has no recollection of the events of that day.

Case 3. A 31-year-old man was in one of the trains involved in a major rail crash. He had been in the guard's van which had split open on impact and he had fallen through the wooden floor. When viewed from below, one of his legs was visible dangling through the floor and the other was hidden under wreckage. He was trapped by the pelvis under the bogey assembly (weight-7 tonnes) of the carriage overlying the guard's van. RC was able to gain access to the patient approximately $2 \mathrm{~h}$ after entrapment. Venous access had already been established but pain relief with Entonox was not adequate. Opiate analgesia was contraindicated for similar reasons to case 2 above. Ketamine $(25 \mathrm{mg})$ was administered, and the dose was repeated at approximately 15 -min intervals. Excellent analgesia was obtained without loss of consciousness or airway compromise. He was extricated after a further $1.5 \mathrm{~h}$ alert, cooperative and painfree; later examination revealed that he had suffered a subtotal traumatic above-knee amputation of the right leg.

Case 4. A 45-year-old businessman lost control of his Audi car on a left-hand bend in a small village. The car spun and collided with a telegraph pole at the apex of the corner. The impact with the B pillar of the car (immediately behind the driver's head) broke the telegraph pole in half approximately $3 \mathrm{~m}$ from the ground and deformed the car into a $\mathrm{C}$ shape around the driver. RC arrived approximately $15 \mathrm{~min}$ after the incident to find the driver trapped in the wreckage, confused and combative, bleeding from the right ear and with an ipsilateral Battle's sign. Venous access had been obtained by the ambulance crew, and physiological variables were satisfactory. After a bolus of $25 \mathrm{mg}$ of ketamine i.v. the driver became calm and manageable. Two further 25-mg doses were administered before he was extricated. He made a full recovery in the regional neurosurgical unit and had no recollection of the accident.

\section{DISCUSSION}

An ideal analgesic agent for use in entrapments should provide rapid, effective pain relief with no vomiting or respiratory depression. The airway and gag reflex should be maintained. Neurological or cardiovascular adverse effects should be insignificant, even in the hypovolaemic patient. It should
Entonox can be given by suitably trained ambulance staff, but it involves relatively bulky equipment, separates into its component gases on cooling (which can occur after as little as $15 \mathrm{~min}$ of use in low ambient temperatures), and cannot be used if the patient is uncooperative or has facial or chest injuries.

Side effects of commonly used opiates, such as pethidine or morphine, include hypotension (particularly in the presence of hypovolaemia) and vomiting. Respiratory depression and loss of the airway may lead to life-threatening hypoventilation if access to the face and neck is limited. This was a potential hazard in cases 2 and 3 . Ambulance staff with extended skills may be able to use nalbuphine, ${ }^{7}$ although this opioid has also been associated with nausea and vomiting, even if respiratory depression is not marked. It also has a ceiling of pain relief equivalent to approximately $10 \mathrm{mg}$ of morphine. ${ }^{8}$

Ketamine is presented in small multi-dose $5-\mathrm{ml}$ ampoules containing 10,50 or $100 \mathrm{mg} \mathrm{ml}^{-1}$. It can be given intravenously, intramuscularly, intrathecally, ${ }^{9}$ and even orally ${ }^{10}$ and rectally. ${ }^{11}$ It provides analgesia in low dose $\left(0.4 \mathrm{mg} \mathrm{kg}^{-1}\right)$ that slides imperceptibly into dissociative general anaesthesia at higher doses $\left(2-4 \mathrm{mg} \mathrm{kg}^{-1}\right.$ by intravenous injection) ${ }^{12}$ without losing the airway, and marked bronchodilatation has been an unexpected benefit. ${ }^{13}$ Loss of the airway is reported as being extremely rare, and then only as a result of a generalized muscular hypertonus affecting the muscles of mastication. ${ }^{14}$ Transient, minimal respiratory depression has been seen very rarely on induction. ${ }^{15}$ These actions have only been recorded with much larger doses ${ }^{16,17}$ than those described here. There was no airway compromise or aspiration of gastric contents by any of these patients. Ketamine tends to maintain the blood pressure, even in the presence of hypovolaemia. ${ }^{4,14}$

In one large series the incidence of emergence phenomena after ketamine was only $2.8 \% .{ }^{18}$ None of our patients had any recollection of the incident, and we saw no objective evidence of emergence phenomena, supporting the view that no benzodiazepine is required. We would suggest that it is contraindicated, because of the known risk of apnoea. $^{19}$

Studies during neurosurgical procedures have shown rises in intracranial pressure, cerebral oxygen consumption and cerebral blood flow in the presence of space-occupying lesions ${ }^{20}$ which has led to the suggestion that ketamine is contraindicated in such cases. However, this response is 
abolished by hypocarbia, which may be provided by controlled ventilation. ${ }^{21}$ Even without control of the carbon dioxide concentration it is arguable that a much greater rise in intracranial pressure is likely to result from the struggling and other inappropriate behaviour frequently seen after moderate head injury.

Recently, ketamine has achieved some notoriety as a drug of abuse,,$^{22}$ and this has led to doctors, particularly general practitioners, having great difficulty in obtaining it. It is not a controlled drug, but many hospital pharmacies have unilaterally decided to make it one, and it can be more difficult to obtain ketamine than diamorphine. There is no evidence that supplies for illicit use are coming from the medical profession, and we would urge that doctors are not denied a valuable agent.

\section{CONCLUSION}

We propose that ketamine may now be considered the analgesic drug of choice for the physician supporting the emergency services outside hospital, and should be considered for all patients requiring safe effective analgesia or anaesthesia, particularly where loss of the airway, apnoea or vomiting may be difficult to manage.

\section{REFERENCES}

1. Dundee J.W., Bovill J., Knox J.W.D., Clarke R.S.J., Black G.W., Love S.H.S., Moore J., Elliott J., Pandit S.K. \& Copple D.L. (1970) Ketamine: a preliminary report on its use as an induction agent. Lancet $\mathbf{i}$, 1370-1371.

2. Bjarnsen W. \& Corssen G. (1967) Cl-581: a new non-barbiturate, short acting anaesthetic for surgery in burns. Michigan Medicine 66, 177.

3. Corssen G. \& Oget S. (1971) Dissociative anaesthesia for the severely burned child. Anaesthetia and Analgesia Current Researches 50, 95-102.

4. Bond A.C. \& Davies C.K. (1974) Ketamine and pancuronium for the shocked patient. Anaesthesia 29, $59-62$.

5. Rust M., Landauer B. \& Kolb B. (1978) Stellenwert von ketamin in der notfallsituation. Der Anaesthesist 27, 205-212.

6. Austin T.R. \& Tamlyn R.S.P. (1972) Ketamine. A revolutionary anaesthetic agent for the battle casualty. Journal of the Royal Army Med Corps 118, 15-23.

7. Stene J.K., Stofberg L., MacDonald G., Myers R.A., Ramzy A. \& Burns B. (1988) Nalbuphine analgesia in the prehospital setting. American Journal of Emergency Medicine 6, 634-639.

8. Hew E. et al. A randomised controlled trial of nalbuphine vs morphine in the treatment of ischaemic chest pain. Current Therapeutic Research 41, 394-402.

9. Bion J.F. (1984) Intrathecal ketamine for war surgery. A preliminary study under war conditions. Anaesthesia 39, 1023-1028.

10. Hain W.R. (1983) Oral ketamine. Anaesthesia 38 , 810-811.

11. Maltby J.R. \& Watkins D.M. (1983) Repeat ketamine anaesthesia of a child for radiotherapy in the prone position. Canadian Anaesthesia Society Journal 30, $526-530$.

12. McCarthy D.A., Chen G., Kaump D.H. \& Ensor C. (1965) General anaesthetic and other pharmocological properties of 2-(0-chlorophenyl)-2-methylamino cyclohexanone $\mathrm{HCl}(\mathrm{Cl}-581)$. Journal of New Drugs 5 , 21-33.

13. Corssen G., Gutierrez J., Reves J.G. \& Huber F.C. Jr. (1972) Ketamine in anaesthetic management of asthmatic patients. Anaesthetia and Analgesia Current Research 51, 588-596.

14. Knox J.W.D., Bovill J.G., Clarke R.S.J. \& Dundee J.W. (1970) Clinical studies of induction agents XXXVI: Ketamine. British Journal of Anaesthesiology 42, 875-885.

15. Coppel D.L. \& Dundee J.W. (1972) Ketamine anaesthesia for cardiac catheterisation. Anaesthesia 27, 25-31.

16. Taylor P.A. \& Towey R.M. (1971) Depression of laryngeal reflexes during ketamine anaesthesia. British Medical Journal ii, 688-689.

17. Taylor P.A., Towey R.M. \& Rappaport A.S. (1972) Further work on the depression of laryngeal reflexes during ketamine anaesthesia using a standard challenge technique. British Journal of Anaesthesiology 44, 1163-1168.

18. Albin M.S. \& Dresner A.J. (1969) Emergence reactions associated with the administration of ketamine hydrochloride (Ketalar, Parke Davis). Paper read before the International Symposium on L'anaesthesie vigile et subvigile, Ostend, Belgium, April 17-20.

19. Forster A., Gardaz J.-P., Suter P.M. \& Gemperle M. (1980) Respiratory depression by midazolam and diazepam. Anaesthesiology 53, 494-497.

20. Takeshita H., Okuda Y. \& Sari A. (1972) The effects of ketamine anaesthesia on cerebral circulation and metabolism in man. Anaesthesiology 36, 69.

21. Sari A., Okuda Y. \& Takeshita H. (1972) The effect of ketamine on cerebrospinal fluid therapy. Anaesthesia and Analgesia Currents Researches 51, 560-566.

22. Jansen K.L.R. (1993) Non-medical uses of ketamine. British Medical Journal 306, 601-602. 